\title{
Acoustic emissions from the inner ear and brain stem responses in type 2 diabetics
}

This article was published in the following Dove Press journal:

International Journal of General Medicine

20 December 20II

Number of times this article has been viewed

\section{Yalda Jabbari Moghaddam}

Department of Otolaryngology, Head and Neck Surgery, Tabriz University of Medical Sciences, Tabriz, Iran
Correspondence: Yalda Jabbari Moghaddam

Otolaryngology Department, Tabriz Children Hospital,

Sheshgelan Ave, Tabriz, Iran

$\mathrm{Tel}+98914|6| 3913$

$\mathrm{Fax}+984$ II 5262270

Email yi_moghaddam@yahoo.com
Background: The purpose of this study was to evaluate the auditory brain stem response (ABR) and acoustic emissions of the inner ear (OAE) in middle-aged type 2 diabetics.

Methods: Fifty type 2 diabetic and nondiabetic patients aged 40-50 years and attending the Tabriz Medical University outpatient clinics were recruited for this study during 2009-2010. All ABR and OAE procedures were implemented by an audiometrist. The relationship between $\mathrm{ABR}$ and $\mathrm{OAE}$ findings and demographic, laboratory, and clinical characteristics was investigated.

Results: Fifty patients ( 34 female and 16 male) of average age $45.7 \pm 3.0$ years were entered into the study. In the type 2 diabetic group, disordered ABR was found in at least one ear in $8 \%$ of cases and disordered OAE was recorded in at least one ear in $16 \%$ of cases, with no significant difference between the diabetic and nondiabetic groups. Mean age, duration of diabetes, serum $\mathrm{HbA}_{1 \mathrm{c}}$ levels, and prevalence of female gender were higher in the diabetic group.

Conclusion: According to our findings, the prevalence of ABR and OAE is not significantly different between type 2 diabetics and nondiabetics.

Keywords: sensorineural hearing loss, diabetes, auditory brain stem response, otoacoustic emission

\section{Introduction}

Technological advances, the increasing prevalence of diabetes, and significance of hearing in people's lives have contributed to a rising number of studies of disordered auditory function in diabetes sufferers. Destruction of the inner hair cells of the cochlea has been reported to be the cause of hearing loss in these people. ${ }^{1,2}$ After exploration of the cochlea structure in diabetics, Fukushima et al proposed cochlear angiopathy and degeneration of the outer hair cells as likely causes of deafness in this group. ${ }^{3}$ Otoacoustic emission (OAE) testing of the inner ear can be helpful for diagnosis of cochlear-related hearing impairment. If the cochlea is damaged, OAE from the cochlea will be disturbed, whereas if the retrocochlear neural pathway is damaged, the OAE will be normal but the auditory brain stem response (ABR) will be abnormal. ${ }^{4,5}$

Simoncelli et al demonstrated that the intensity and amplitude of recorded waves for OAE in diabetics were significantly lower than in a control group, and attributed this to a disorder in the hair cells of the cochlear. ${ }^{6}$ Nowadays, a number of educational institutions are equipped with $\mathrm{OAE}$ and ABR testing facilities, and given the numerous diabetics in our region, the importance of hearing, and lack of research on the subject, we evaluated $\mathrm{OAE}$ and $\mathrm{ABR}$ in a group of type 2 diabetics. 


\section{Materials and methods}

Our study was performed at Tabriz University of Medical Sciences over a period of 12 months from August 2009 to September 2010. The study was approved by the ethical committee of the Islamic Azad University of Tabriz. Fifty type 2 diabetic patients and 50 healthy nondiabetic individuals aged 40-50 years were recruited for ABR and OAE testing. Exclusion criteria included congenital hearing loss from childhood, trauma-induced hearing loss, and a history of chronic otitis media. A full medical history and examination was performed for all patients. The ABR and OAE tests were then performed separately by an expert audiologist. The standards for ABR (90 dB nHL, 30 impulses, click $125 \mathrm{msec}$ half-wave squared) used were: I, $1.97 \mathrm{msec}$; III, $4.2 \mathrm{msec}$; V, $6.2 \mathrm{msec}$; interpeak latency: I-III, $2.2 \mathrm{msec}$; III-V, 2 msec; and I-V, $4.2 \mathrm{msec}$.

Diagnostic decisions were based on measurement of $\mathrm{V}$ wave latency and its interural latency. Demographic, laboratory, and clinical data were sought by a questionnaire devised in the Tabriz Medical Science Department. The information recorded included family history, past medical history, blood pressure, cholesterol levels, fasting blood sugar, $\mathrm{HbA}_{1 \mathrm{c}}$, and serum creatinine levels. The questionnaire had been pretested in a small pilot population and modified as necessary.

\section{Statistical analysis}

The Mann-Whitney U test was used to compare quantitative data and Fisher's Exact test was used to compare qualitative data. In all cases, $P \leq 0.05$ was considered to be statistical significant.

\section{Results}

Sixteen subjects (32\%) were male and 34 were female $(68 \%)$. Mean age was $45.7 \pm 3.0$ years. Average weight was $80.3 \pm 15.8$ (range 50-145) kg. Mean duration of disease in the diabetic group was $8.2 \pm 5.1$ years. At admission, mean fasting blood sugar was $171.2 \pm 68.3(83-395) \mathrm{mg} / \mathrm{dL}$, mean $\mathrm{HbA}_{1 \mathrm{c}}$ was $8.0 \pm 1.6(5.1-12)$ percent, and mean serum creatinine was $0.9 \pm 0.2(0.5-1.8) \mathrm{mg} / \mathrm{dL}$. There were complaints of hearing loss in $18(36 \%)$ cases, having noise in the ear in nine (18\%) cases, and vertigo in $21(42 \%)$ cases. Thirty-eight (76\%) diabetic patients had high cholesterol, 20 (40\%) had hypertension, three $(6 \%)$ had ischemia, and one $(2 \%)$ had anemia. Examination of the ears was normal in all cases. Forty (80\%) were using metformin, 27 (54\%) glibenclamide, $11(22 \%)$ insulin, two (4\%) a glitazone, $30(60 \%)$ aspirin, 25 (50\%), atorvastatin, four ( $8 \%$ ) atenolol, and one each (2\%) was on clonazepam, propranolol, nitrocantin, and fluoxetine.

Abnormal ABR was recorded in the right ear in four $(8 \%)$ cases (one deafness, three $30 \mathrm{~dB}$ hearing loss) and in the left ear in three $(6 \%)$ cases (30 dB hearing loss). Three cases suffered from bilateral hearing loss of $30 \mathrm{~dB}$ on average. The most common finding in ABR was increased $\mathrm{V}$ wave latency. Abnormal OAE was found in both ears in seven (14\%) cases, in the right ear in eight (16\%) cases, and in the left ear in seven $(14 \%)$ cases. Both abnormal ABR and OAE was found in four $(8 \%)$ cases and either abnormal ABR or OAE was found in one ear in eight (16\%) cases. Comparison of data collected by questionnaire based on the presence or absence of abnormal ABR in one ear is summarized in Table 1. There was no statistically significant difference between any of the variables. Tables 2-4 summarize the comparison of variables according to the presence or absence of abnormal OAE in at least one ear.

\section{Discussion}

In diabetics, we found abnormal ABR in at least one ear in $8 \%$ of cases, abnormal OAE in at least one ear in $16 \%$ of cases,

Table I Comparison of demographic, clinical, and laboratory characteristics according to existence of disordered ABR and OAE in one ear in diabetic patients

\begin{tabular}{llll}
\hline Variable & $\begin{array}{l}\text { Normal ABR and OAE } \\
(\mathbf{n}=\mathbf{4 6})^{*}\end{array}$ & $\begin{array}{l}\text { Abnormal ABR and OAE } \\
(\mathbf{n}=\mathbf{4})\end{array}$ \\
\hline Age (years) & $(48) 48 \pm 2$ & $(46) 46 \pm 3$ & $\mathbf{P}$ \\
Gender (male) & $(35) 16$ & $(0) 0$ & 0.256 \\
Duration of diabetes (years) & $(7) 8 \pm 2$ & $(6) 8 \pm 5$ & 0.495 \\
HbA $_{\text {Ic }}$ (\%) & $(9) 9 \pm 2$ & $(8) 8 \pm 2$ & 0.593 \\
Serum creatinine (mg/dL) & $(1) 1 \pm 0$ & $(1) 1 \pm 0$ & 0.928 \\
High cholesterol & $(76) 35$ & $(75) 3$ & 0.928 \\
High blood pressure & $(4 I) 19$ & $(25) 1$ & 0.679 \\
Complaint of hearing loss & $(35) 16$ & $(50) 2$ & 0.472 \\
Existing noise in ear & $(20) 9$ & $(0) 0$ & 0.456 \\
Complaint of vertigo & $(39) 18$ & $(75) 3$ & 0.444 \\
\hline Note: 16 & & 0.193 \\
\hline
\end{tabular}

Note: "All values after $\mathrm{n}$ values are ranges.

Abbreviations: $A B R$, auditory brain stem response; $O A E$, acoustic emission of inner ear. 
Table 2 Comparison of demographic, clinical, and laboratory characteristics according to existence of disordered ABR in one ear in diabetic patients

\begin{tabular}{|c|c|c|c|}
\hline Variable & $\begin{array}{l}\text { Normal ABR and OAE } \\
(n=46)^{*}\end{array}$ & $\begin{array}{l}\text { Abnormal ABR and OAE } \\
(n=4)\end{array}$ & $P$ \\
\hline Age (years) & (46) $46 \pm 3$ & (48) $48 \pm 2$ & 0.256 \\
\hline Gender (male) & (35) 16 & (0) 0 & 0.201 \\
\hline Duration of diabetes (years) & (6) $8 \pm 5$ & (7) $8 \pm 2$ & 0.593 \\
\hline $\mathrm{HbA}_{\mathrm{Ic}}(\%)$ & (8) $8 \pm 2$ & (9) $9 \pm 2$ & 0.307 \\
\hline Serum creatinine $(\mathrm{mg} / \mathrm{dL})$ & (I) $I \pm 0$ & (I) $I \pm 0$ & 0.928 \\
\hline High cholesterol & (76) 35 & (75) 3 & 0.679 \\
\hline High blood pressure & (4I) 19 & (25) I & 0.472 \\
\hline Complaint of hearing loss & (35) 16 & (50) 2 & 0.456 \\
\hline Existing noise in ear & (20) 9 & (0) 0 & 0.440 \\
\hline Complaint of vertigo & (39) 18 & (75) 3 & 0.193 \\
\hline
\end{tabular}

Note: ${ }^{*}$ All values after $\mathrm{n}$ values are ranges.

Abbreviations: $A B R$, auditory brain stem response; $O A E$, acoustic emission of inner ear.

abnormal $\mathrm{ABR}$ or OAE in at least one ear in $16 \%$ of cases, and an abnormality of both ABR and OAE in at least one ear in $8 \%$ of cases. Soveid et al compared tonic and verbal audiometry in 80 diabetics of mean age 49 years with a control group of 78 healthy nondiabetics. Hearing loss and speech impairment was noted more often in the diabetic group than in controls, but the difference was not statistically significant, ${ }^{7}$ and hearing loss was reported to be significantly greater in the diabetic group. Konrad-Martin et al investigated ABR in 166 diabetics and 138 healthy controls under the age of 50 years, and reported significantly more cases of disordered ABR in the diabetic group. ${ }^{8}$ Lisowska et al studied 42 diabetics aged 21-42 years and 33 healthy controls using $\mathrm{ABR}$ and $\mathrm{OAE}$, and reported that latency of ABR was significantly greater and that OAE amplitude was significantly reduced in the diabetic group. ${ }^{9}$ They concluded that there is a disorder in the central micromechanical cochlear and retrocochlear auditory pathways in diabetics. Ottaviani et al compared 60 insulin-dependent diabetics of average age
31 years with 58 controls using OAE. In their study, 28.3\% had impaired OAE in one ear and $10 \%$ had impaired OAE in both ears, ${ }^{10}$ and it was concluded that there is cochleopathy in diabetes. Orts Alborch et al investigated 20 diabetics and 20 healthy controls using OAE. In their study, amplitude was significantly lower than in controls, and they hypothesized that the cochlear disorder in diabetics arises from altered function of the outer hair cells. ${ }^{11}$

In the present study, we investigated additional variables potentially involved in auditory damage in diabetics. We found that average age, duration of diabetes, serum $\mathrm{HbA}_{1 \mathrm{c}}$, and preponderance of female gender was higher in diabetics with disordered ABR and OAE than in controls. However, these differences did not reach statistical significance, although the difference in $\mathrm{HbA}_{1 \mathrm{c}}$ level was more marked than for the other variables.

The results of the different studies in this field vary widely, with some reporting that age, duration of disease, and $\mathrm{HbA}_{1 \mathrm{c}}$

Table 3 Comparison of demographic, clinical, and laboratory characteristics according to existence of disordered OAE in one ear in diabetic group

\begin{tabular}{llll}
\hline Variance & $\begin{array}{l}\text { Normal ABR and OAE } \\
(\mathbf{n}=\mathbf{4 6})^{*}\end{array}$ & $\begin{array}{l}\text { Abnormal ABR and OAE } \\
(\mathbf{n}=\mathbf{4})\end{array}$ \\
\hline Age (years) & $(46) 46 \pm 3$ & $(47) 46 \pm 4$ & $\mathbf{P}$ \\
Gender (male) & $(33) 14$ & $(25) 2$ & 0.541 \\
Duration of diabetes (years) & $(6) 8 \pm 5$ & $(8) 9 \pm 3$ & 0.495 \\
HbA $_{\text {Ic }}$ (\%) & $(7) 8 \pm 2$ & $(9) 9 \pm 2$ & 0.099 \\
Serum creatinine (mg/dL) & $(1) 1 \pm 0$ & $(1) 1 \pm 0$ & $(63) 5$ \\
High cholesterol & $(79) 33$ & $(25) 2$ & 0.067 \\
High blood pressure & $(43) 18$ & $(50) 4$ & 0.314 \\
Complaint of hearing loss & $(33) 14$ & $(25) 2$ & 0.287 \\
Existing noise in ear & $(17) 7$ & $(63) 5$ & 0.297 \\
Complaint of vertigo & $(38) 16$ & & 0.303 \\
\hline Not 16 & & & 0.445 \\
\hline
\end{tabular}

Note: "All values after $\mathrm{n}$ values are ranges.

Abbreviations: $A B R$, auditory brain stem response; $O A E$, acoustic emission of inner ear. 
Table 4 Comparison of demographic, clinical, and laboratory characteristics according to existence of disordered ABR or OAE in one ear in diabetic patients

\begin{tabular}{|c|c|c|c|}
\hline Variability & $\begin{array}{l}\text { Normal ABR and OAE } \\
(n=46)^{*}\end{array}$ & $\begin{array}{l}\text { Abnormal ABR and OAE } \\
(n=4)\end{array}$ & $P$ \\
\hline Age (years) & (47) $46 \pm 4$ & (46) $46 \pm 3$ & 0.541 \\
\hline Gender (male) & (33) 14 & (25) 2 & 0.495 \\
\hline Duration of diabetes (years) & (8) $9 \pm 3$ & (6) $8 \pm 5$ & 0.099 \\
\hline $\mathrm{HbA}_{\mathrm{Ic}}(\%)$ & (9) $9 \pm 2$ & (7) $8 \pm 2$ & 0.067 \\
\hline Creatinine serum $(\mathrm{mg} / \mathrm{dL})$ & (I) $I \pm 0$ & (I) $I \pm 0$ & 0.314 \\
\hline High cholesterol & (79) 33 & (63) 5 & 0.287 \\
\hline High blood pressure & (43) 18 & (25) 2 & 0.297 \\
\hline Complaint of hearing loss & (33) 14 & (50) 4 & 0.303 \\
\hline Existing noise in ear & (I7) 7 & (25) 2 & 0.445 \\
\hline Complaint of vertigo & (38) 16 & (63) 5 & 0.186 \\
\hline
\end{tabular}

Note: "All values after $\mathrm{n}$ values are ranges.

Abbreviations: $A B R$, auditory brain stem response; OAE, acoustic emission of inner ear.

levels are correlated with hearing impairment, and others not being able to replicate these observations. We did not include patients over 50 years of age because this age group has an increased rate of presbyacusia, which is a type of sensorineural hearing loss. Our results, especially for $\mathrm{HbA}_{1 \mathrm{c}}$, suggest that our diabetic population was well trained in diabetes control, had good compliance with medication, attended clinic regularly, and had a disease duration of less than 10 years. This could have contributed to the low rate of ocular and renal side effects reported on their questionnaires. If our diabetic sample size was larger and/or had been selected at random from the community, our results may have been different. Many of the side effects of diabetes are potentially controllable with appropriate instruction and consistent blood sugar control. Raising public awareness about diabetes and regular follow-up of patients can play a key role in the control of this disease and its side effects.

\section{Conclusion}

Our study did not detect any significant acoustic emission disorder of the inner ear or brain stem in type 2 diabetics. However, larger and preferably multicenter studies would be needed to confirm our negative findings.

\section{Acknowledgment}

We thank Mrs Ayda Ariafar for her helpful assistance in $\mathrm{ABR}$ and $\mathrm{OAE}$ measurement and data collection.

International Journal of General Medicine

\section{Publish your work in this journal}

The International Journal of General Medicine is an international, peer-reviewed open-access journal that focuses on general and internal medicine, pathogenesis, epidemiology, diagnosis, monitoring and treatment protocols. The journal is characterized by the rapid reporting of reviews, original research and clinical studies across all disease areas.

\section{Disclosure}

The author reports no conflicts of interest in this work.

\section{References}

1. Erdem T, Ozturan O, Miman MC, et al. Exploration of the early auditory effects of hyperlipoproteinemia and diabetes mellitus using otoacoustic emissions. Eur Arch Otorhinolaryngol. 2003;260(2):62-66.

2. Brands AM, Biessels GJ, de Haan EH, et al. The effects of type 1 diabetes on cognitive performance: a meta-analysis. Diabetes Care. 2005;28(3):726-735.

3. Fukushima H, Cureoglu S, Schachern PA, et al. Effects of type 2 diabetes mellitus on cochlear structure in humans. Arch Otolaryngol Head Neck Surg. 2006;132(9):934-938.

4. Cummings CW, Haughey BH, Thomas JR, Harker LA, Flint PW. Cummings Otolaryngology: head and Neck Surgery. 4th ed. Philadelphia, PA: Mosby; 2004.

5. Nadol JB, Randolph GW. Clinical Handbook of Ear Nose and Throat Disorders. 5th ed. New York, NY: Informa Healthcare; 2004.

6. Simoncelli C, Ricci G, Molini E, et al. Evoked acoustic oto-emissions in patients with diabetes mellitus. Ann Otolaryngol Chir Cervicofac. 2002;110(5):255-258. French.

7. Soveid M, Kaviani M, Behgam M, et al. Investigation of hearing disturbances in diabetic patients. Iran J Diabetes Lipid Disord. 2003; 2(45):105-109.

8. Konrad-Martin D, Austin DF, Griest S, et al. Diabetes-related changes in auditory brainstem responses. Laryngoscope. 2010;120(1):150-158.

9. Lisowska G, Namysłowski G, Morawski K, et al. Otoacoustic emissions and auditory brain stem responses in insulin dependent diabetic patients. Otolaryngol Pol. 2002;56(2):217-225. Polish.

10. Ottaviani F, Dozio N, Neglia CB, et al. Absence of otoacoustic emissions in insulin-dependent diabetic patients: is there evidence for diabetic cochleopathy? J Diabetes Complications. 2002;16(5):338-343.

11. Orts Alborch M, Morant Ventura A, García Callejo J, et al. The study of otoacoustic emissions in diabetes mellitus. Acta Otorrinolaringol Esp. 1998;49(1):25-28. Spanish.

\section{Dovepress}

A key focus is the elucidation of disease processes and management protocols resulting in improved outcomes for the patient.The manuscript management system is completely online and includes a very quick and fair peer-review system. Visit http://www.dovepress.com/ testimonials.php to read real quotes from published authors. 